\title{
Boundary-Layer Effect in Robust Sliding Mode Control for Indirect Field Oriented Control of 3-Phase Induction Motor
}

\author{
Dedid Cahya Happyanto ${ }^{1}$, Angga Wahyu Aditya ${ }^{2}$ and Bambang Sumantri ${ }^{3}$ \\ ${ }^{1,3}$ Department of Electrical Engineering, Politeknik Elektronika Negeri Surabaya, Surabaya, Indonesia \\ ${ }^{2}$ Department of Electrical Engineering, Politeknik Negeri Balikpapan, Balikpapan, Indonesia \\ dedid@pens.ac.id, angga.wahyu@poltekba.ac.id, bambang@pens.ac.id
}

\begin{abstract}
High-performance control systems for induction motors (IM) such as Indirect Field Oriented Control (IFOC) which are applied to induction motors are widely used for industry and electric vehicle. IFOC represents the mathematical model of an induction motor similar to a DC motor. Therefore, this system is easy to design and implement. A Robust and stable control methods such as Sliding Mode Control (SMC) must be added to ensure its robustness and stability. The drawback of SMC is the high frequency chattering phenomenon that comes from the discontinuous control inputs. However, it could harm the hardware and increase power consumption. Therefore, a boundary layer function is applied in SMC for rotor speed control using the saturation function. This puts a limit on the chattering phenomenon in certain areas. The results show by replacing sign function with saturation function in FOSMC reduces the chattering phenomenon in rotor speed and electromagnetic torque response (transient and steady-state condition), decrease stator current in direct and quadrature axis, and saving power consumption.
\end{abstract}

Keywords: IFOC system, SMC, induction motor, and boundary layer

\section{Nomenclature}

\begin{tabular}{|c|c|c|c|c|c|}
\hline Frequency & 50 & $\mathrm{~Hz}$ & $f$ & Rotor speed reference & $\Omega r *$ \\
\hline Rotor & & & & Stator voltage in direct axis & $U_{d s}$ \\
\hline Resistance & 6.085 & $\Omega$ & $R$ & Stator voltage in quadrature axis & 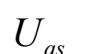 \\
\hline $\begin{array}{l}\text { Stator } \\
\text { Resistance }\end{array}$ & 6.03 & $\Omega$ & Rs & & \\
\hline Rotor & & & & Stator current in direct axis & $d s$ \\
\hline $\begin{array}{l}\text { Inductance } \\
\text { Stator }\end{array}$ & 0.4893 & $\mathrm{H}$ & $L r$ & $\begin{array}{l}\text { Stator current in direct axis } \\
\text { reference }\end{array}$ & $i_{d s} *$ \\
\hline Inductance & 0.4893 & $\mathrm{H}$ & $L$ & Stator current in quadrature axis & $i_{q s}$ \\
\hline $\begin{array}{l}\text { Mutual } \\
\text { Inductance } \\
\text { Number of }\end{array}$ & 0.4503 & $\mathrm{H}$ & $L m$ & $\begin{array}{l}\text { Stator current in quadrature axis } \\
\text { reference }\end{array}$ & $i_{q s} *$ \\
\hline Pole Pairs & 2 & & $H$ & Rotor flux in direct axis & $\Phi_{r d}$ \\
\hline $\begin{array}{l}\text { Moment of } \\
\text { Inertia }\end{array}$ & 0.00488 & $\mathrm{Kg} \cdot \mathrm{m}^{2}$ & $j$ & Rotor flux in quadrature axis & $\Phi_{r q}$ \\
\hline Stator speed & & & $\Omega s$ & Rotor flux reference & $\Phi r *$ \\
\hline Slip speed & & & $\Omega s l$ & & \\
\hline Rotor speed & & & $\Omega r$ & & \\
\hline
\end{tabular}

\section{Introduction}

Nowadays, the IM is widely used as the main actuator component in the industrial world and electric vehicle more than the other electric motors (DC motor, Permanent Magnet Synchronous

Received: August $14^{\text {th }}, 2018$. Accepted: May $7^{\text {th }}, 2020$

DOI: $10.15676 /$ ijeei.2020.12.2.2 
Motor (PMSM) and Switched Reluctance Motor (SRM)) [1], [2]. The IM has better performance in controllability, reliability, technology maturity and low cost than the other electric motor. On the other hand, the power density and efficiency of PMSM is better than IM [3], [4]. Because of these reasons, Tesla uses IM as the main engine in Tesla Model S [5]. There are two methods to control an IM, scalar and vector control. Scalar control is chosen because of its simplicity and ease of use but has low performance. The IFOC system that part of vector control has better performance than scalar control nowadays can be applied and accepted by the electric drive market in the industrial world than Direct Field Oriented Control (DFOC) [6], [7]. The IFOC system represents the complicated mathematical model of IM similarly DC motor in linearity, decoupling and high-performance control of AC drive. In the IFOC system, decouple control between flux and electromagnetic torque is possible [8].

Research of the IFOC system has been developed in recent years to obtain the control method of IM that is efficient, robust, and stable [9], [10], [11], [12], [13]. However, the IFOC system can not guarantee the stability and robustness of the system. control methods need to add to achieve robustness and stability against the disturbances. The IFOC system consists of two loops. The first loop called the outer loop which includes the rotor speed and flux controller and the second loop called the inner loop is the current regulator (direct and quadrature stator current controller). Therefore, the cascade robust controller should be designed in both of the loops to obtain the robustness and stability of the IFOC system. In reality, the conventional control methods for the IFOC system is designed with the simplest controller such as proportional (P), proportional-integral (PI), and proportional-integral-derivative (PID) controllers [14], [15]. However, PI and PID use the tuning method such as gain scheduling and numerical tuning to set the parameters of proportional $(\mathrm{Kp})$, integral $(\mathrm{Ki})$ and derivative $(\mathrm{Kd})$ [16]. In advanced control methods, the most commonly used for the IFOC system is fuzzy, neural network and genetic algorithm whether in an intelligent or an adaptive control algorithm [17], [18], [19]. These control methods aim to achieve stability and robustness but very difficult to prove. A robust controller such as SMC, the stability and the robustness can be achieved simultaneously. In SMC, the stability of the system guaranteed by the Lyapunov stability theory while the robustness by $\operatorname{sign}($.$) function [20].$

In the last decade, the development of a robust controller in the IFOC system has been done in the current regulator (direct stator current controller) and speed controller using standard SMC or First Order SMC (FOSMC) [21], [22]. FOSMC guarantees the robustness and stability of the IFOC system. On another hand, FOSMC has disadvantages in the chattering phenomenon [23], [24]. It caused by the discontinuous control law of FOSMC to guarantee robustness and stability. The magnitude of chattering depended on the robust constant of sign function. However, this chattering may causes damage on the hardware. Therefore, it is important to reduce the chattering in FOSMC. A thin boundary layer designed using saturation function can be a solution in a robust speed controller of the IFOC system to reduce the chattering phenomenon in FOSMC. In this paper, the effectiveness of chattering reduction in FOSMC for IFOC is evaluated. Verification and validation of control methods is performed in MATLAB/Simulink.

Analysis of the effects of boundary layers by using saturation function in FOSMC is the main objective of this paper. This paper organized as follows in section 2 discusses IM mathematical model and the IFOC system. Section 3 discusses the IFOC system based robust SMC. Section 4 shows the results and discussion of the FOSMC and boundary layer in SMC. Finally, the conclusion discusses in section 5.

\section{IFOC System}

Figure 1 shows the basic concept of the IFOC system. The rotor speed reference $(\Omega r *)$ works as the main input. The rotor flux reference $\left(\Phi r^{*}\right)$ is generated from the lookup table based on the rotor speed reference data. The current regulator reference $\left(i_{d s} *\right.$ and $i_{q s} *$ ) comes 
from the output of the rotor speed and flux controller. As a result, the IFOC system uses a cascade controller which affect each other.

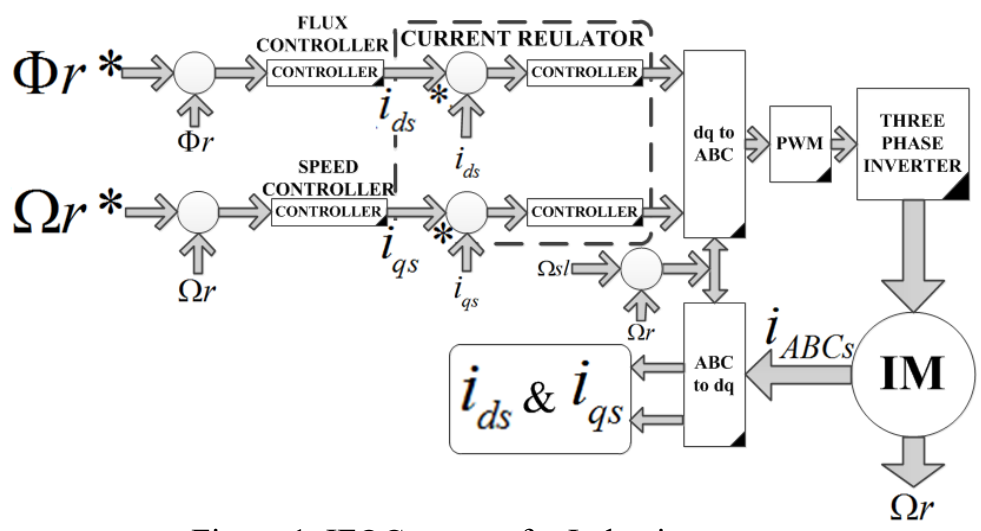

Figure 1. IFOC system for Induction motor

The IFOC system mathematical models can be achieved from an IM model in a stationary or rotating frame. In general, it is used the rotating frame which is shown in (1) [25].

$$
\dot{X}=A X+B U
$$

where :

$$
\begin{aligned}
& A=\left[\begin{array}{cccc}
-R m / \sigma L s & \Omega s & R r L m / L r^{2} \sigma L s & L m \Omega r / L r \\
\Omega s & -R m / \sigma L s & L m \Omega r / L r & R r L m / L r^{2} \sigma L s \\
L m / T r & 0 & -1 / T r & \Omega s l \\
0 & L m / T r & \Omega s l & -1 / T r
\end{array}\right], X=\left[\begin{array}{c}
i_{d s} \\
i_{q s} \\
\Phi_{r d} \\
\Phi_{r q}
\end{array}\right], \quad B=\left[\begin{array}{c}
1 / \sigma L s \\
1 / \sigma L s \\
0 \\
0
\end{array}\right] ; \\
& \text { and } U=\left[\begin{array}{c}
U_{d s} \\
U_{q s} \\
0 \\
0
\end{array}\right]
\end{aligned}
$$

with $R m=R s+\frac{L m^{2}}{L r^{2}} R r, \Omega s l=\Omega s-\Omega r, T r=L r / R r$ is rotor time constant and $\sigma=1-L m^{2} /(L s+L r)$ is total leakage factor.

The mechanical modeling of an IM consists of a rotor speed equation shown in (2).

$$
\frac{d \Omega r}{d t}=\frac{L m}{j L r}\left(\Phi_{r d} i_{q s}-\Phi_{r q} i_{d s}\right)-\frac{m_{o}}{j}
$$

with $j$ is the inertia moment and $m_{o}$ is the torque load. The electromagnetic torque equation $\left(m_{e}\right)$ shown in (3).

$$
m_{e}=\frac{3}{2} P \frac{L m}{L r}\left(\Phi_{r d} i_{q s}-\Phi_{r q} i_{d s}\right)
$$

In the IFOC system that shown in Figure 1, the electromagnetic torque and rotor flux of the IM can be controlled separately. It makes an IM mathematical model similar to a DC motor. The 
IFOC system mathematical models come from IM mathematical model in the rotating frame (DQ frame) which shown in (4).

$$
\Phi_{r d}=\Phi_{r} \text { and } \Phi_{r q}=0
$$

From (1) (2) and (4), the IFOC system mathematical models are as follow :

Rotor speed equation:

$$
\frac{d \Omega r}{d t}=\frac{L m}{j L r}\left(\Phi_{r} i_{q s}\right)-\frac{m_{o}}{j}
$$

where the electromagnetic torque equation becomes:

$$
m_{e}=\frac{3}{2} P \frac{L m}{L r}\left(\Phi_{r} i_{q s}\right)
$$

The correlation between rotor speed and electromagnetic torque from (5) and (6) is shown in (7).

$$
\frac{d \Omega r}{d t}=\frac{2}{3 P j} m_{e}-\frac{m_{o}}{j}
$$

Rotor flux equation:

$$
\frac{d \Phi r}{d t}=\frac{L m}{T r} i_{d s}-\frac{1}{T r} \Phi r
$$

Stator current in DQ frame (current regulator) equation using state-space representation shown in (9).

$$
\dot{x}_{i}=A_{i} x_{i}+B_{i} U_{i}+C_{i} \Phi r
$$

where :

$$
x_{i}=\left[\begin{array}{l}
i_{d s} \\
i_{q s}
\end{array}\right], A_{i}=\left[\begin{array}{cc}
\frac{-R m}{\sigma L s} & \Omega s \\
\Omega s & \frac{-R m}{\sigma L s}
\end{array}\right], B_{i}=\left[\begin{array}{cc}
1 / \sigma L s & 0 \\
0 & 1 / \sigma L s
\end{array}\right] \text { and } C_{i}=\left[\begin{array}{c}
L m / L r T r \\
L m / \Omega s l
\end{array}\right]
$$

\section{The IFOC System Based Robust SMC}

In designing SMC, the sliding surface to obtain a sliding mode regime shown in (10) that guarantees the convergence of the system must be determined first.

$$
S(e)=\left(\frac{d}{d t}+\lambda\right)^{n-1} e
$$

where $S(e)$ is sliding surface equation, $\lambda$ and $n$ are positive constant and $e=x-x_{d}$ with $x$ and $x_{d}$ are state variable and desired state vectors, respectively.

The SMC consists of two parts shown in (11). The first is equivalent control $\left(U_{e q}\right)$ designed from the dynamic modeling of the IFOC system by using Lyapunov method and the other one to ensure robustness $\left(U_{n}\right)$.

$$
U_{c}=U_{e q}+U_{n}
$$

Lyapunov function $(V)$ for this SMC controller uses:

$$
V=1 / 2 S(e)^{2}
$$


Hence, the derivative of (12) is:

$$
\dot{V}=S(e) \cdot \dot{S}(e)
$$

A simple form of a control signal to guarantee robustness is the sign function shown in (14).

$$
U_{n}=K_{x} S(e)+\delta_{x} \operatorname{sign}(S(e))
$$

where $K_{x}$ and $\delta_{x}$ are positive robustness constants.

In designing the IFOC system based on FOSMC, the value of $n$ in (10) must be " 1 ". In consequence, the FOSMC control methods for the IFOC system of rotor speed and flux controller are:

FOSMC of rotor speed equation is :

$$
U_{c}\left(m_{e}\right)=\frac{3}{2} j P\left(\Omega \dot{r} *+\frac{m_{o}}{j}\right)+K_{1} S_{1}(\Omega r)+\delta_{1} \operatorname{sign}\left(S_{1}(\Omega r)\right)
$$

FOSMC of rotor flux equation is :

$$
U_{c}\left(i_{d s}\right)=\frac{T r}{L m}\left(\dot{\Phi r} *+\frac{1}{T r} \Phi r\right)+K_{2} S_{2}(\Phi r)+\delta_{2} \operatorname{sign}\left(S_{2}(\Phi r)\right)
$$

FOSMC for current regulator can be designed from state-space representation by substituting (9) to the derivative of Lyapunov function shown in (13) to get the control signal shown in (17).

$$
U_{c}\left(x_{i}\right)=B_{i}^{-1}\left(\dot{x}_{d i}-A_{i} x_{i}-C_{i} \Phi r\right)+K_{x i} S\left(x_{i}\right)+\delta_{x i} \operatorname{sign}\left(S\left(x_{i}\right)\right)
$$

where : $B_{i}^{-1}=\left[\begin{array}{cc}\sigma L s & 0 \\ 0 & \sigma L s\end{array}\right]$ is invers of matrix B.

From (17), the FOSMC design for the current regulator in direct stator current is:

$$
U_{c}\left(U_{d s}\right)=\sigma L s\left(i_{d s} *+\frac{R m}{\sigma L s} i_{d s}-\Omega s i_{q s}-\frac{L m}{\operatorname{LrTr}} \Phi r\right)+K_{i_{d s}} S\left(i_{d s}\right)+\delta_{i_{d s}} \operatorname{sign}\left(S\left(i_{d s}\right)\right)
$$

while the FOSMC design for the current regulator in quadrature stator current is:

$$
U_{c}\left(U_{q s}\right)=\sigma L s\left(i_{q s} *+\frac{R m}{\sigma L s} i_{q s}-\Omega s i_{d s}-\frac{L m \Omega s l}{L r} \Phi r\right)+K_{i_{q s}} S\left(i_{q s}\right)+\delta_{i_{q s}} \operatorname{sign}\left(S\left(i_{q s}\right)\right)
$$

The saturation function is proposed to reduce the chattering phenomenon in standard SMC. This saturation function is placed in the rotor speed equation in (15). This is used to analyze and calculate the effect of the boundary layer in the IFOC system. The saturation function applied in FOSMC for rotor speed control shown in (20).

$$
U_{c}\left(m_{e}\right)=\frac{3}{2} j P\left(\Omega \dot{r} *+\frac{m_{o}}{j}\right)+K_{1} S_{1}(\Omega r)+\beta_{l} \operatorname{sat}\left(S_{1}(\Omega r)\right)
$$

Where:

$$
\operatorname{sat}\left(S_{1}(\Omega r)=\left\{\begin{array}{c}
\operatorname{sign}\left(S_{1}(\Omega r)\right) \\
S_{1}(\Omega r) / \beta_{l}
\end{array}\right.\right.
$$

with $\beta_{l}$ is positive boundary layer constant.

\section{Result and Discussion FOSMC Evaluation}

Performance of boundary layer in FOSMC evaluated in rotor speed, electromagnetic torque, and stator current responsein. the boundary layer placed in a speed controller while the current regulator and rotor flux use original FOSMC. Table 1 shows the constant parameter of the 
Dedid Cahya Happyanto, et al.

FOSMC $\left(\lambda, K\right.$, and $\delta$ ) and boundary layer $\left(\beta_{l}\right)$ in the IFOC system. This constant parameter is tune intuitively. The rotor speed reference of the IFOC system is set in the 1.400 rpm in no-load condition. The response of the rotor speed with and without boundary layer at FOSMC is close to the given set point. Figure 2(a) shows the chattering phenomenon in the rotor speed response using FOSMC in the speed controller while figure 2(b) using FOSMC with the boundary layer. The chattering phenomenon in figure 2(b) is smaller than figure (a) due to the boundary layer. The electromagnetic torque response of FOSMC shown in figure 3(a) using FOSMC with sign function and the boundary layer shown in figure $3(\mathrm{~b})$. The stator currents response appears as time-invariant in DQ rotating reference frame as presented in figure 4(a) and 4(b). The stator current response of FOSMC with sign function shows in 4(a) while the saturation function in $4(\mathrm{~b})$.

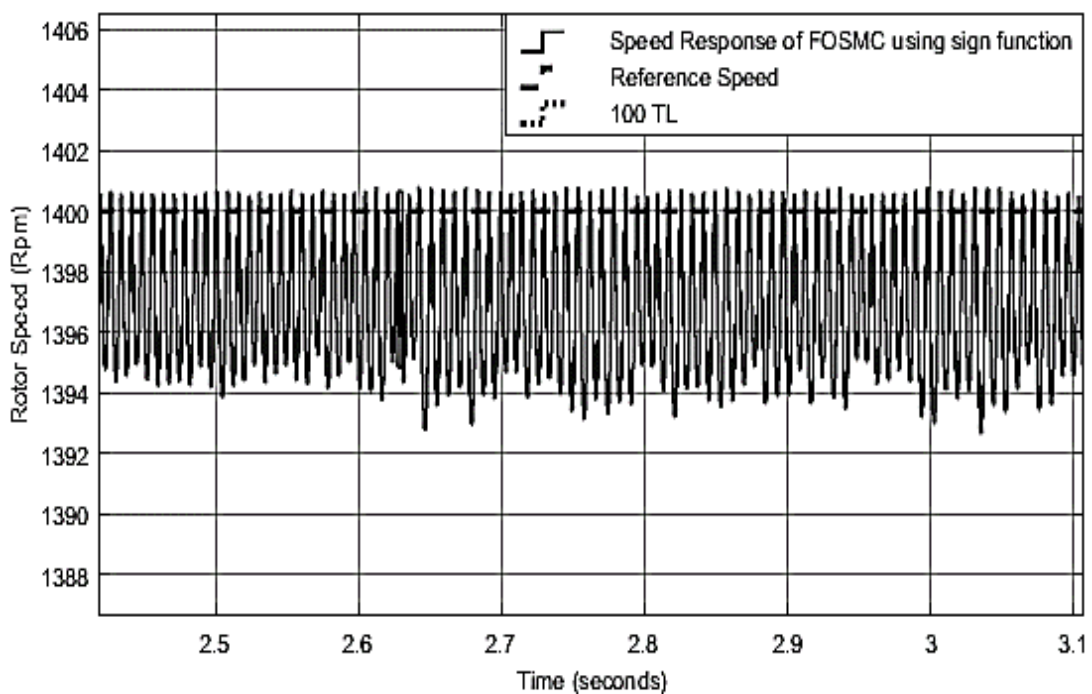

(a)

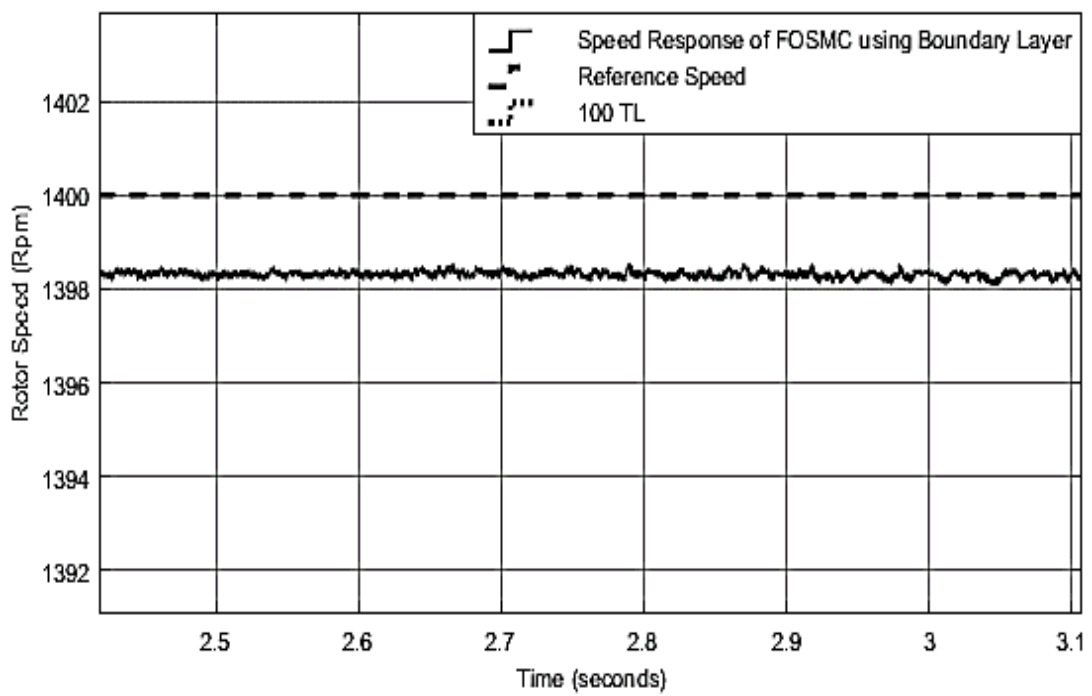

(b)

Figure 2. Rotor speed response in no-load condition (a) FOSMC using sign function (b) FOSMC using saturation function 
Table 1. Constant parameter

\begin{tabular}{|c|c|c|c|c|}
\hline \multirow{2}{*}{ Motor Parameter } & \multicolumn{3}{|c|}{ FOSMC Parameter } & Boundary SMC Parameter \\
\cline { 2 - 5 } & $\lambda$ & $K$ & $\delta$ & $\beta_{l}$ \\
\hline$i_{d s}$ & 25.00 & 15.00 & 25.00 & - \\
\hline$i_{q s}$ & 25.00 & 15.00 & 25.00 & - \\
\hline$\Phi r$ & 0.10 & 0.10 & 0.50 & - \\
\hline$\Omega r$ & 0.80 & 0.25 & 2.50 & 1.5 \\
\hline
\end{tabular}

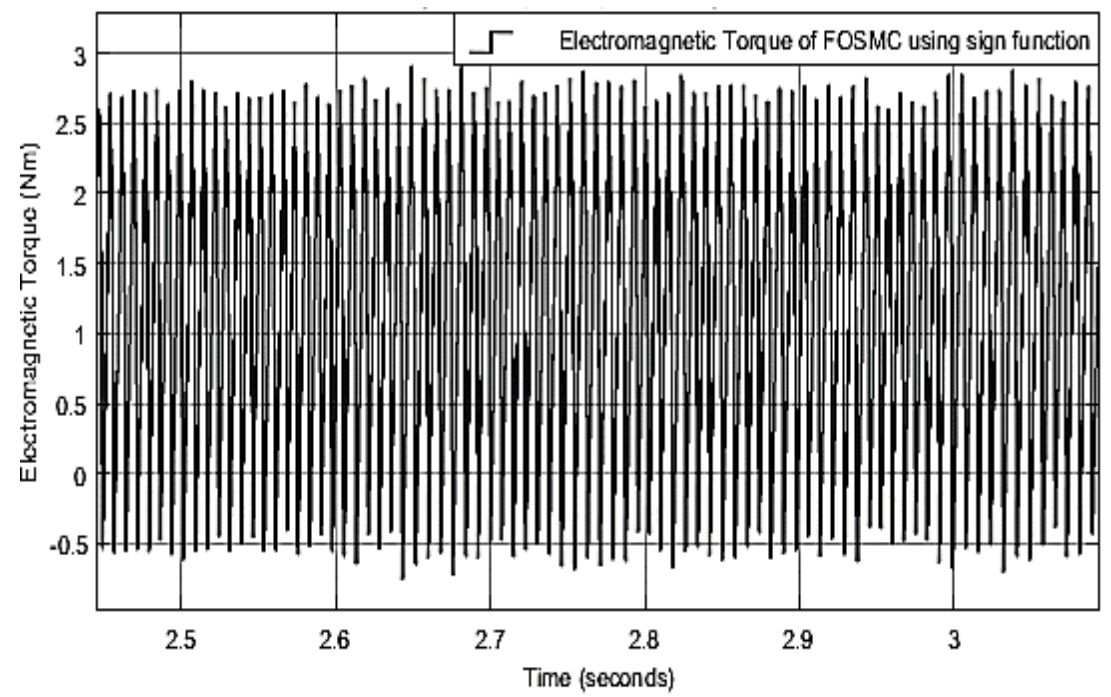

(a)

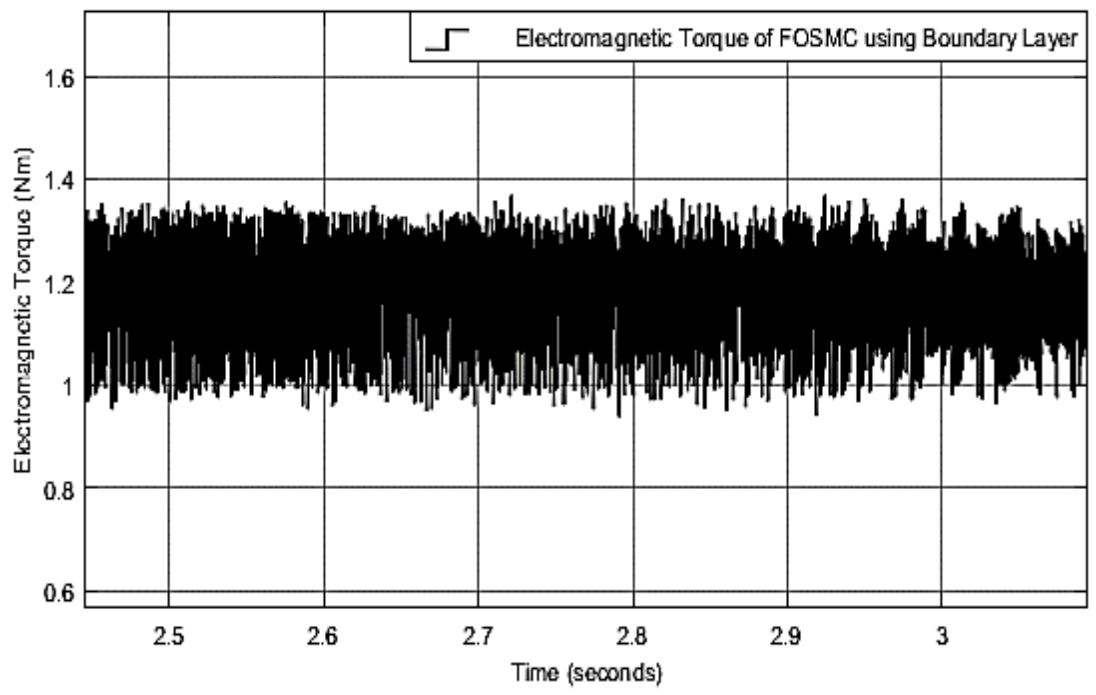

(b)

Figure 3. Electromagnetic torque response in no-load condition (a) FOSMC using sign function

(b) FOSMC using saturation function 


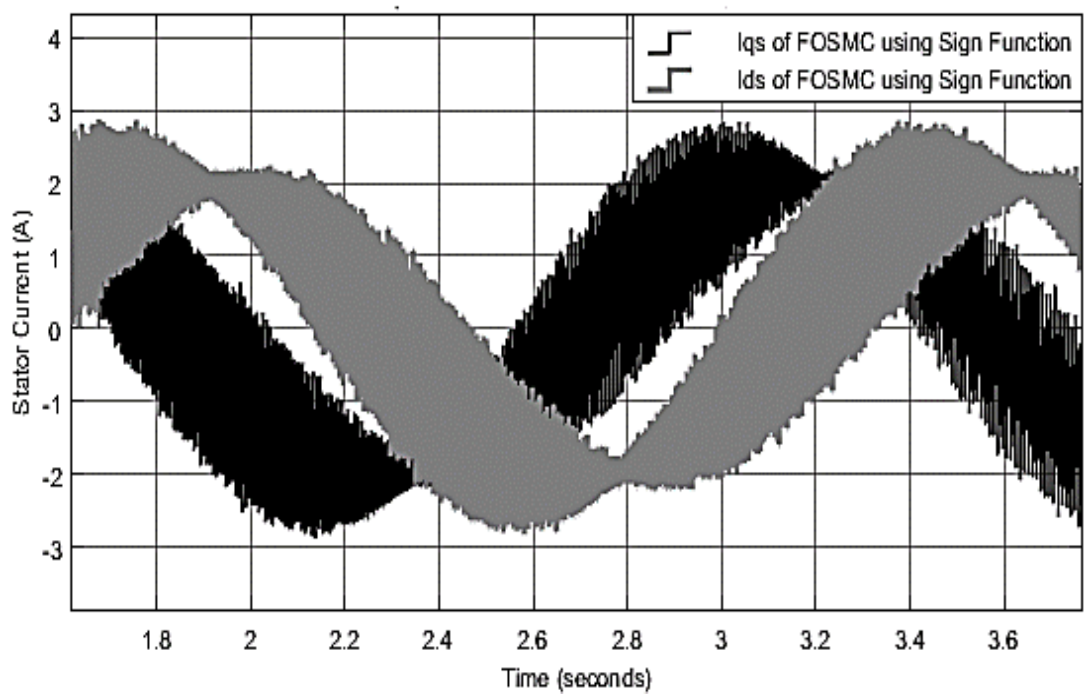

(a)

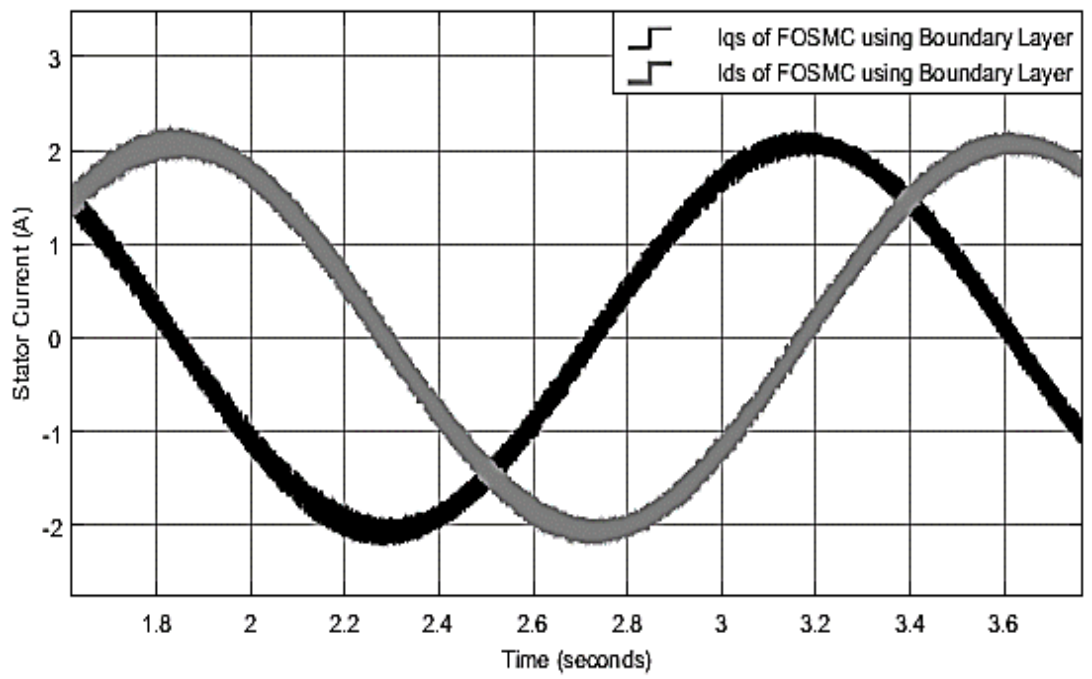

(b)

Figure 4. Stator current ( $i_{d s}$ and $i_{q s}$ ) response in no-load condition (a) FOSMC using sign function (b) FOSMC using saturation function

\section{Robustness and Chattering Reduction Evaluation}

The robustness of FOSMC verified by constant rotor speed test with variable torque load and variable rotor speed test with constant torque load. The constant rotor speed tests the reference rotor speed is $1400 \mathrm{rpm}$ with torque loads are $0,5 \mathrm{Nm}, 1 \mathrm{Nm}$, and 1,5 Nm. Temporary, the reference rotor speed in variable speed test are $1.100 \mathrm{rpm}$ at $0-2$ seconds, $1.350 \mathrm{rpm}$ at $2-4$ seconds, $900 \mathrm{rpm}$ at $4-6$ second, $1.200 \mathrm{rpm}$ at $6-8$ seconds and $1.000 \mathrm{rpm}$ at $8-10$ seconds. The robustness analisys works at rotor speed response in overshoot, rise time, and average error (transient and steady-state condition). 
Table 2. Response of the IFOC system based FOSMC with constant rotor speed reference

\begin{tabular}{|c|c|c|c|c|c|c|c|c|}
\hline \multirow{3}{*}{ Parameters } & \multicolumn{4}{|c|}{ FOSMC using sign Function } & \multicolumn{4}{|c|}{ FOSMC using sat Function } \\
\hline & \multicolumn{4}{|c|}{ Torque Load (Nm) } & \multicolumn{4}{|c|}{ Torque Load (Nm) } \\
\hline & 0 & 0,5 & 1 & 1,5 & 0 & 0,5 & 1 & 1,5 \\
\hline \multicolumn{9}{|c|}{ Stator Current Response } \\
\hline$i_{d s}(\mathrm{~A})$ & 1,75 & 1,96 & 1,97 & 2,35 & 1,55 & 1,74 & 1,808 & 2,37 \\
\hline$i_{q s}(\mathrm{~A})$ & 1,69 & 1,90 & 2,01 & 2,40 & 1,56 & 1,70 & 1,82 & 2,41 \\
\hline \multicolumn{9}{|c|}{ Power Response } \\
\hline Active Power (W) & 3.915 & 3.938 & 4.135 & 4.416 & 2.370 & 2.633 & 3.315 & 4.059 \\
\hline $\begin{array}{l}\text { Reactive Power } \\
\text { (VAR) }\end{array}$ & 3.704 & 3.896 & 4.184 & 4.413 & 2.587 & 2.999 & 3.582 & 4.309 \\
\hline $\begin{array}{l}\text { Apparent Power } \\
\text { (VA) }\end{array}$ & 5.389 & 5.540 & 5.883 & 6.243 & 3.509 & 3.991 & 4.881 & 5.919 \\
\hline \multicolumn{9}{|c|}{ Rotor Speed (RS) Response } \\
\hline Overshoot $(\%)$ & 0,505 & 0,505 & 0,505 & 0,505 & 0,505 & 0,505 & 0,505 & 0,505 \\
\hline Rise time (ms) & 736 & 761 & 787 & 813 & 738 & 759 & 785 & 815 \\
\hline $\begin{array}{l}\text { Average error in } \\
\text { RS (\%) } \\
\text { (transient) }\end{array}$ & 1,70 & 1,82 & 1,93 & 2,00 & 1,25 & 1,38 & 1,54 & 1,66 \\
\hline $\begin{array}{l}\text { Average error in } \\
\text { RS (\%) } \\
\text { (steady-state) }\end{array}$ & 0,27 & 0,72 & 0,80 & 0,84 & 0,12 & 0,08 & 0,06 & 0,04 \\
\hline \multicolumn{9}{|c|}{ Electromagnetic Torque (Tem) Response } \\
\hline $\begin{array}{l}\text { Average error in } \\
\text { Tem } \quad(\%) \\
\text { (transient) }\end{array}$ & 152,00 & 112,58 & 88,77 & 73,33 & 88,87 & 71,72 & 61,81 & 54,20 \\
\hline $\begin{array}{l}\text { Average error in } \\
\text { Tem }(\%) \\
\text { (steady-state) }\end{array}$ & 71,19 & 64,05 & 50,53 & 41,47 & 6,65 & 4,66 & 2,99 & 2,53 \\
\hline
\end{tabular}

The constant rotor test with variable torque load results shown in table 2. This test takes the stator current response, power analysis, rotor speed response, and electromagnetic response as a success parameter. The DQ rotating frame is used to analyze the stator's current response. The direct stator current $\left(i_{d s}\right)$ response for FOSMC using sign function has an average increase of $10,60 \%$ while the quadrature current $\left(i_{q s}\right)$ response has $12,54 \%$. The FOSMC using saturation function (boundary layer) has a bigger an average increase than using sign function in 15,75\% for $i_{d s}$ and $16,15 \%$ for $i_{q s}$ although in root-mean-square (RMS) value FOSMC with saturation function smaller than sign function. Power analysis consists of active, reactive, and apparent power response analysis under no-load conditions and torque loads of $0,5 \mathrm{Nm}, 1 \mathrm{Nm}$, and 1,5 $\mathrm{Nm}$. The saturation function reduce the active power response $39,46 \%$ in no-load condition, $33,14 \%$ under $0,5 \mathrm{Nm}$ of torque load, $19,83 \%$ under $1 \mathrm{Nm}$ of torque load, and 8,08\% under 1,5 $\mathrm{Nm}$ of torque load. This reduction also occurs in reactive and apparent power. The percentage reduction in power analysis is significantly reduced due to the saturation function that cannot withstand robustness and stability when the response exits the sliding region. Performance at rotor speed response that is shown in figure 5(a) and 5(b) analysis in overshoot, rise time, and average error (transient and steady-state condition) while the electromagnetic torque is in average error (transient and steady-state condition). The robustness of FOSMC using sign 
Dedid Cahya Happyanto, et al.

function in rotor speed response shown in figure 5(c) for transient condition and figure 5(e) for the steady-state condition. At the same time, the robustness of FOSMC using the saturation function shown in figure 5(d) for transient condition and figure 5(f) for the steady-state condition. On one hand, The FOSMC using sign function and saturation function have the same response in overshoot and rise time both in no-load condition and in various torque loads. On another hand, the FOSMC using saturation function is better than sign function at the average error of rotor speed and electromagnetic torque in transient and steady-state conditions. The robustness validation has shown by the average error in rotor speed that less than $2 \%$ in steadystate conditions with various torque loads. The saturation function design in the rotor speed controller makes a significant impact on electromagnetic torque response. In no-load response, the average error of electromagnetic torque response reduced $63,13 \%$ in transient conditions while $64,54 \%$ in the steady-state conditions. The electromagnetic torque response with $0,5 \mathrm{Nm}$ of torque load shown in figure 6(a) for FOSMC using sign function and figure 6(b) for FOSMC using saturation function. Table 2, figure 6(c), 6(d), 6(e) and 6(f) show the electromagnetic torque response under $0,5 \mathrm{Nm}$ of torque load reduced in both transient and steady-state conditions. At transient conditions, it reduces $40,86 \%$ while at steady-state conditions $59,39 \%$.

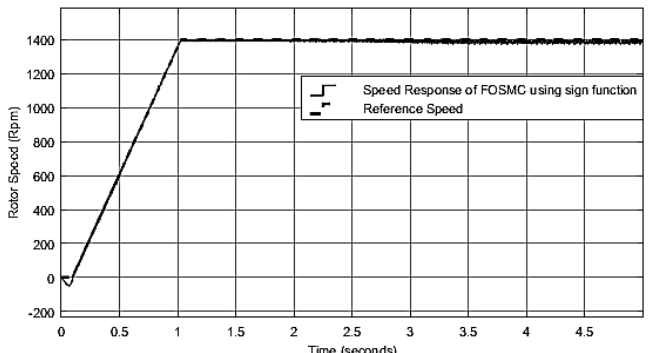

(a)

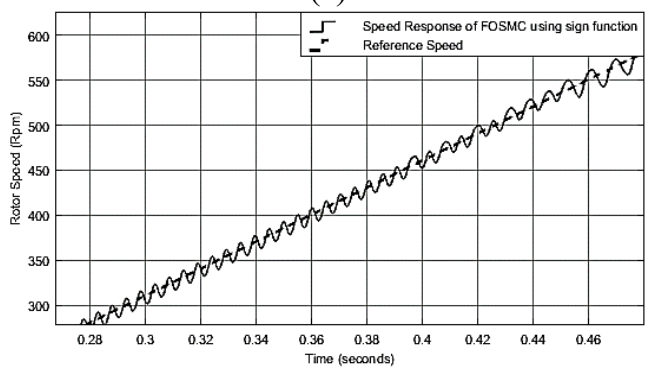

(c)

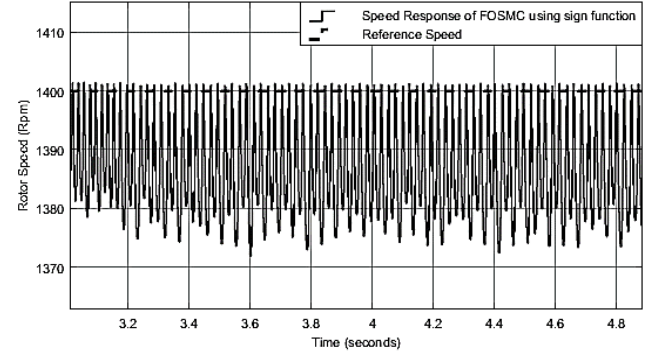

(e)

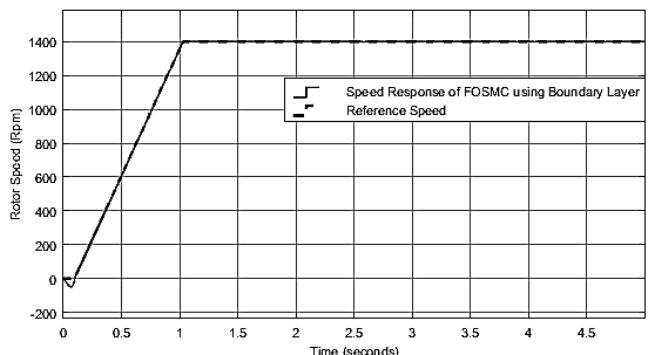

(b)

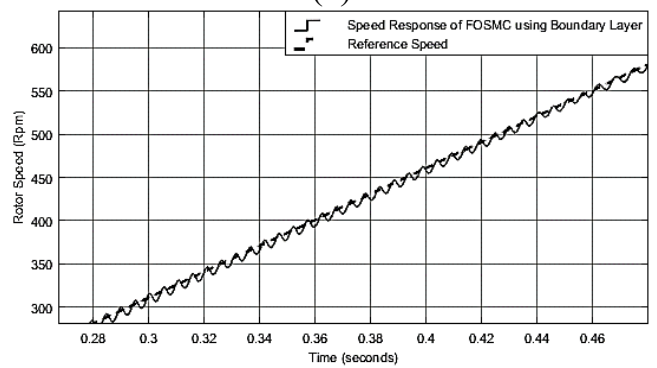

(d)

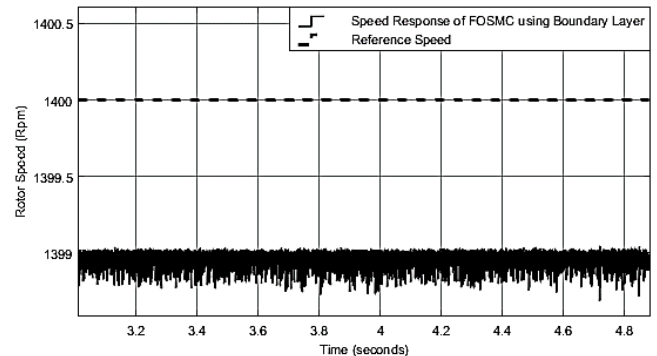

(f)

Figure 5. Rotor speed response with torque load $=0,5 \mathrm{Nm}$ (a) FOSMC using sign function, (b) FOSMC using saturation function, (c) transient condition of FOSMC using sign function, (d) transient condition of FOSMC using saturation function, (e) steady-state condition of FOSMC using sign function, (f) steady-state condition of FOSMC using saturation function 


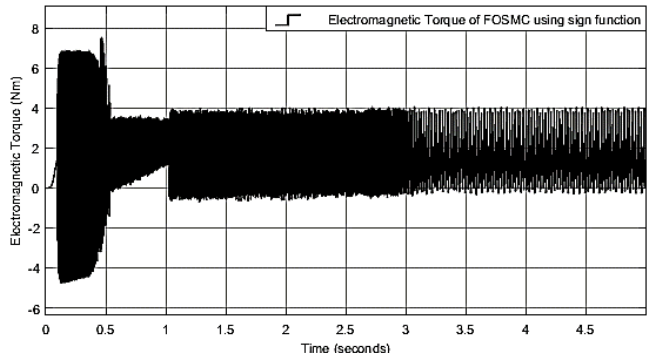

(a)

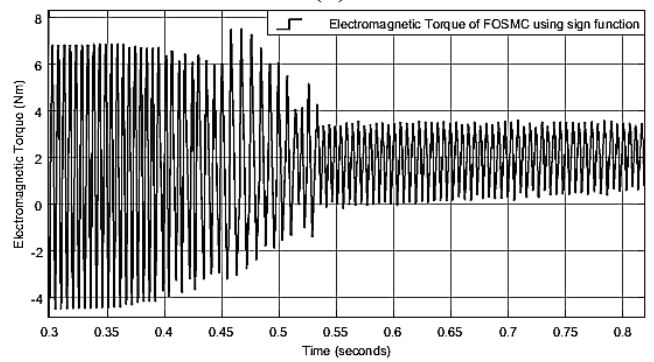

(c)

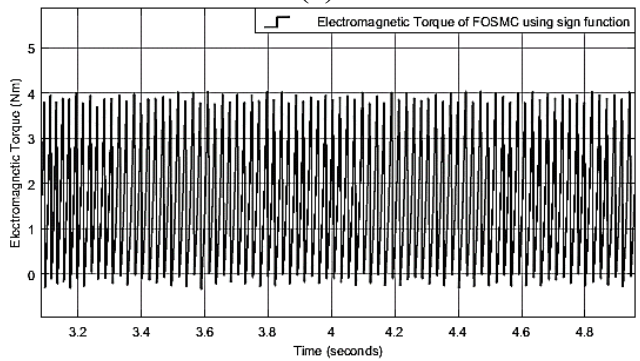

(e)

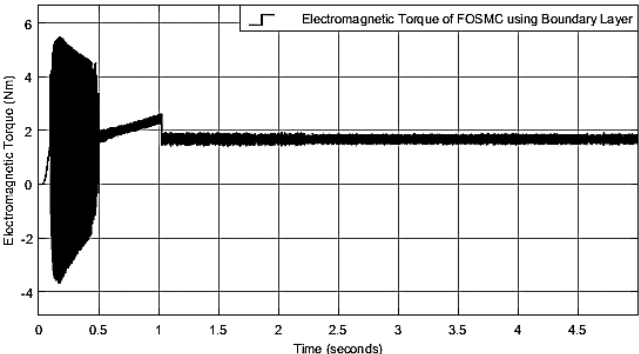

(b)

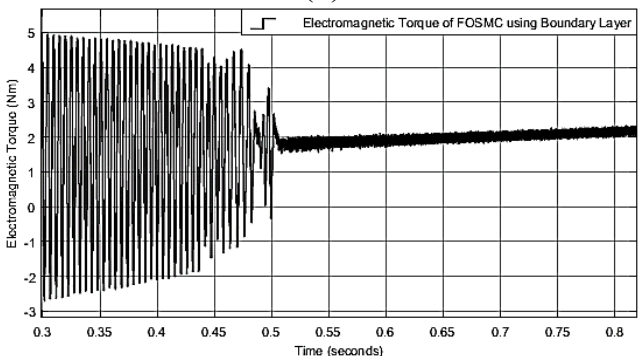

(d)

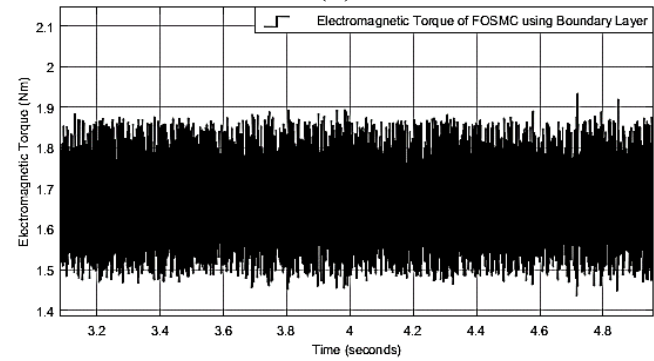

(f)

Figure 6. Electromagnetic torque response with torque load $=0,5 \mathrm{Nm}$ (a) FOSMC using sign function, (b) FOSMC using saturation function, (c) transient condition of FOSMC using sign function, (d) transient condition of FOSMC using saturation function, (e) steady-state condition of FOSMC using sign function, (f) steady-state condition of FOSMC using saturation function

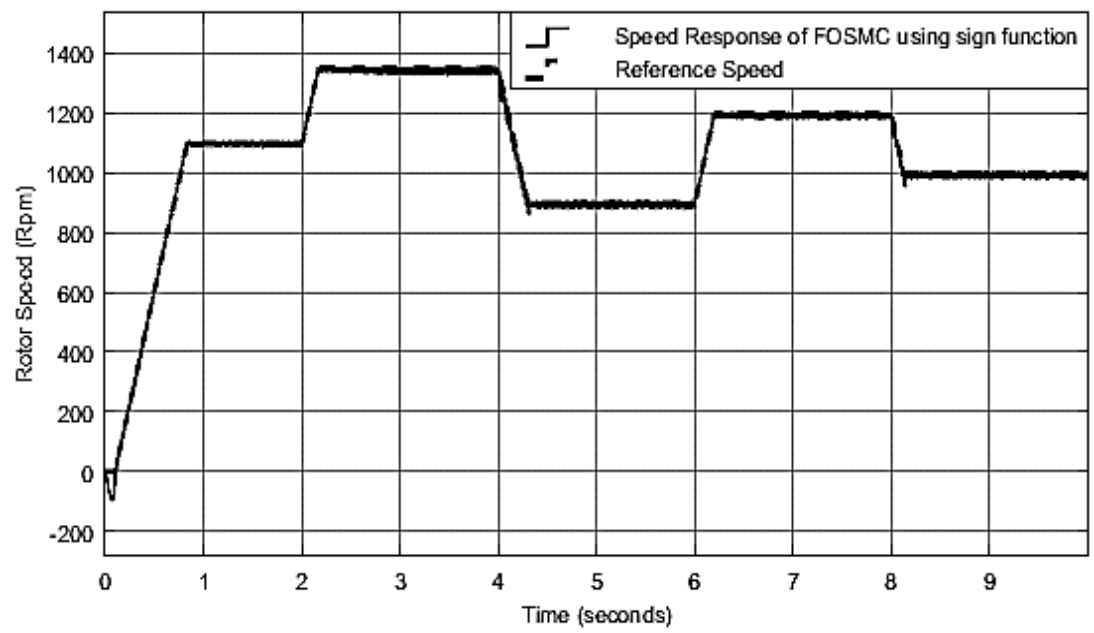

Figure 7. Rotor speed response using sign function in variable reference speed with $1 \mathrm{Nm}$ of torque load 
Dedid Cahya Happyanto, et al.

The variable rotor speed test designed with $1 \mathrm{Nm}$ of torque load and variable rotor speed references. Figure 7 shows the rotor speed response of FOSMC using sign function and figure 8 shows the FOSMC using saturation function. The robustness analysis of FOSMC is carried out at each transient and steady-state condition at each rotor speed reference. The robustness of the FOSMC is evidenced by the steady-state error at each rotor speed reference of less than $2 \%$, both FOSMC using sign function and saturation function. Figure 9 proves that FOSMC usng saturation function gives better performance than using sign function in variable rotor speed test with constant torque load.

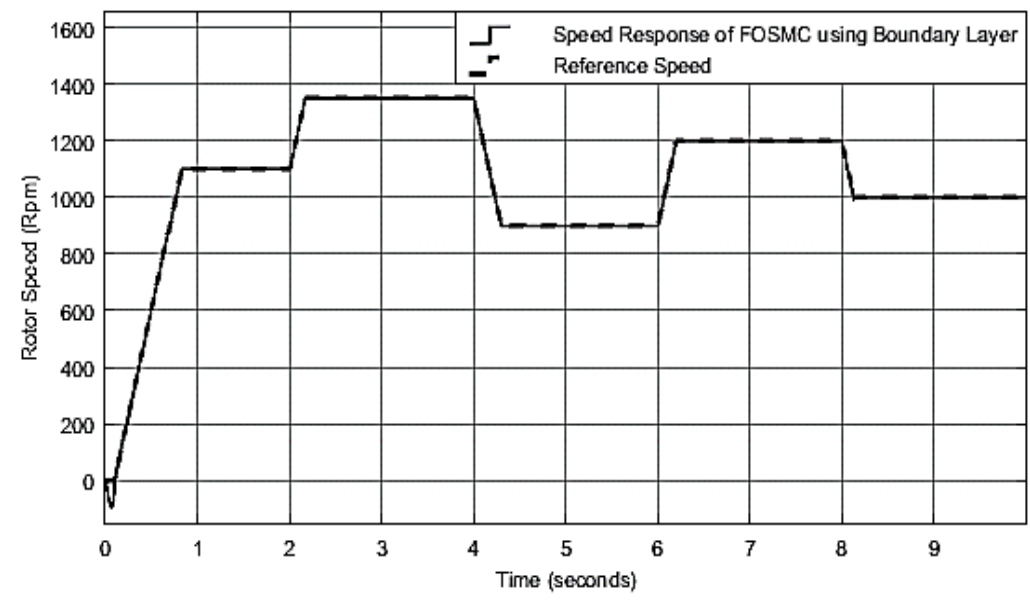

Figure 8. Rotor speed response using saturation function in variable reference speed with $1 \mathrm{Nm}$ of torque load

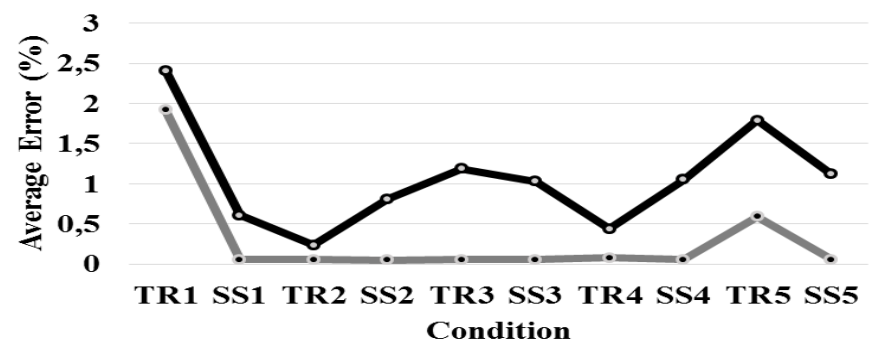

Figure 9. Average error of rotor speed in variable reference speed with $1 \mathrm{Nm}$ of torque load

Table 3. Chattering reduction in constant rotor speed reference with variable torque load $($ reference speed $=1.400 \mathrm{rpm})$

\begin{tabular}{|l|c|c|c|c|c|}
\hline \multicolumn{2}{|c|}{ Parameters } & \multicolumn{4}{c|}{ Torque Load (Nm) } \\
\cline { 2 - 6 } & $\begin{array}{c}\text { Transient } \\
\text { Condition }\end{array}$ & $0,15 \%$ & $0,64 \%$ & $0,74 \%$ & $0,80 \%$ \\
\cline { 2 - 6 } Rotor Speed (\%) & $\begin{array}{c}\text { Steady-State } \\
\text { Condition }\end{array}$ & $0,45 \%$ & $0,44 \%$ & $0,39 \%$ & $0,34 \%$ \\
\hline \multirow{2}{*}{$\begin{array}{l}\text { Electromagnetic } \\
\text { Torque (\%) }\end{array}$} & $\begin{array}{c}\text { Transient } \\
\text { Condition }\end{array}$ & $63,13 \%$ & $40,86 \%$ & $26,96 \%$ & $19,13 \%$ \\
\cline { 2 - 6 } & $\begin{array}{c}\text { Steady-State } \\
\text { Condition }\end{array}$ & $64,54 \%$ & $59,39 \%$ & $47,54 \%$ & $38,94 \%$ \\
\hline
\end{tabular}




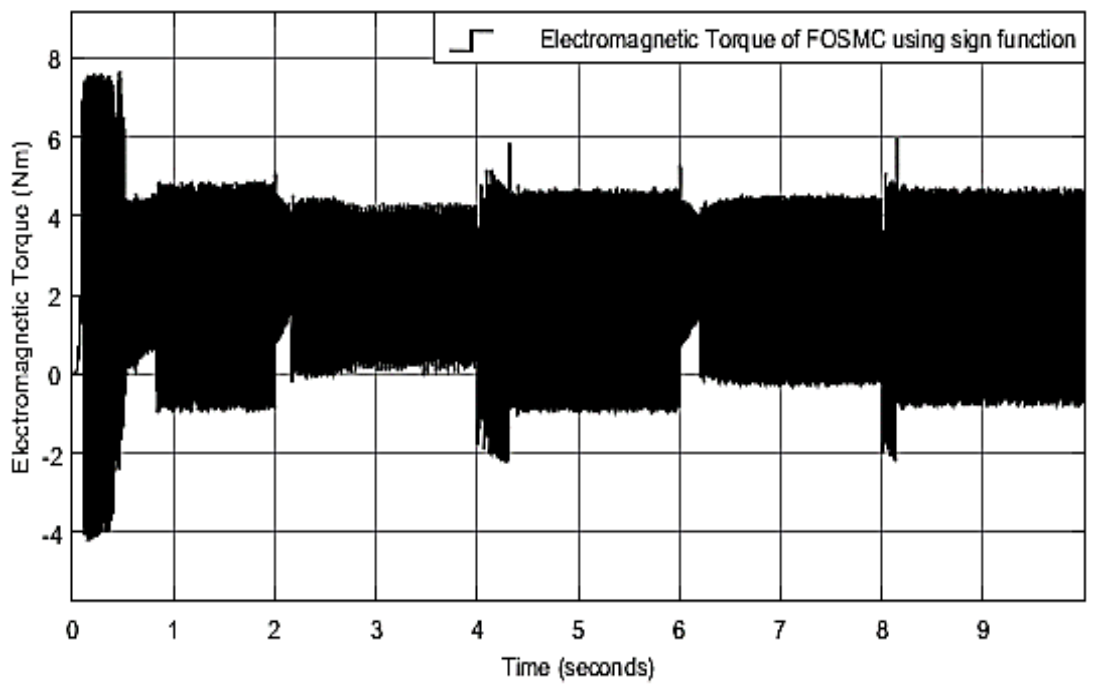

Figure 10. Electromagnetic torque response using sign function in variable reference speed with $1 \mathrm{Nm}$ of torque load

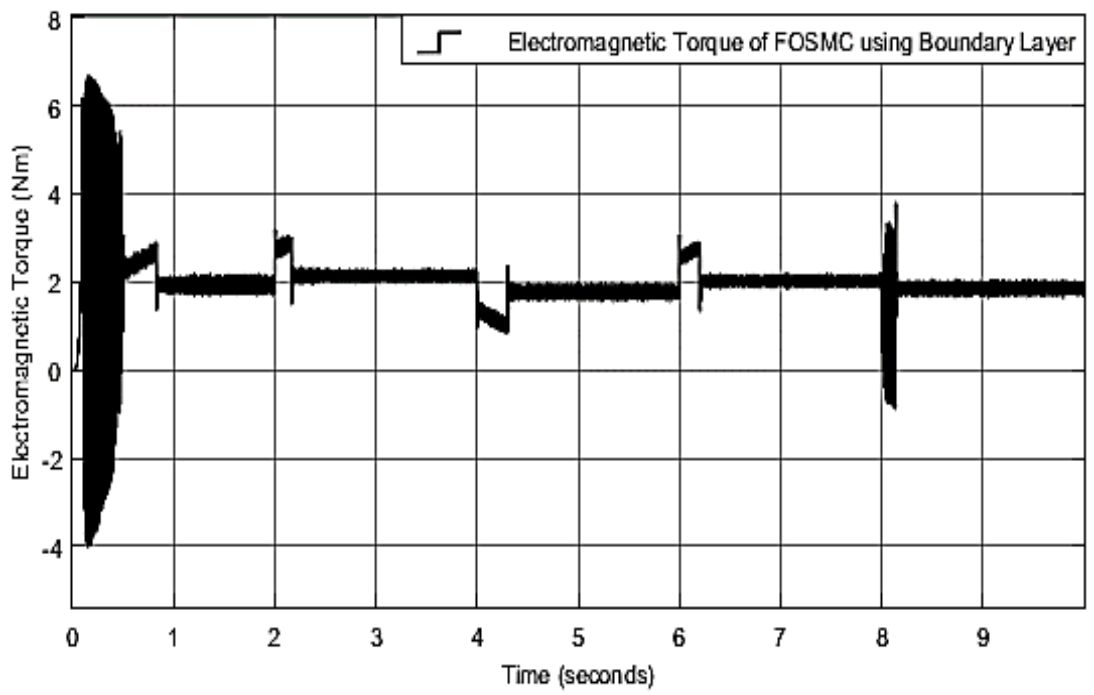

Figure 11. Electromagnetic torque response using saturation function in variable reference speed with $1 \mathrm{Nm}$ of torque load

The chattering evaluation purposes the chattering reduction in rotor speed and electromagnetic torque. The chattering reduction illustrations are shown in electromagnetic torque in figure 10 and figure 11. Figure 10 shows the electromagnetic torque response of FOSMC using the sign function. By replacing sign function with saturation function in FOSMC, the chattering phenomenon in electromagnetic torque significantly reduced as shown in figure 11. The concept of chattering reduction measurement based on average percentage error in each condition (transient and steady-state) that shown in table 3 and table 4. This chattering reduction uses to analyze the boundary layer effect in the speed controller and electromagnetic torque response. 
Table 4. variable rotor speed reference test results (torque load $=1 \mathrm{Nm}$ )

\begin{tabular}{|c|c|c|c|c|c|c|}
\hline \multicolumn{2}{|c|}{ Condition } & \multicolumn{3}{|c|}{ Power Reduction } & \multicolumn{2}{|c|}{ Chattering Reduction } \\
\hline & & $\mathrm{P}(\%)$ & $\mathrm{Q}(\%)$ & $\mathrm{S}(\%)$ & RS (\%) & Tem $(\%)$ \\
\hline \multirow{2}{*}{$\begin{array}{l}0 \mathrm{~s}-2 \mathrm{~s} \\
1.100 \mathrm{rpm}\end{array}$} & TR1 & 28,85 & 14,45 & 24,17 & 0,49 & 30,07 \\
\hline & SS1 & 23,59 & 21,92 & 23,00 & 0,55 & 70,56 \\
\hline \multirow{2}{*}{$\begin{array}{l}2 \mathrm{~s}-4 \mathrm{~s} \\
1.350 \mathrm{rpm}\end{array}$} & TR2 & 22,08 & 23,95 & 22,85 & 0,18 & 26,66 \\
\hline & $\mathrm{SS} 2$ & 21,46 & 21,86 & 21,63 & 0,76 & 50,23 \\
\hline \multirow{2}{*}{$\begin{array}{l}4 s-6 s \\
900 \mathrm{rpm}\end{array}$} & TR3 & 20,83 & 20,17 & 20,52 & 1,13 & 138,19 \\
\hline & SS3 & 20,25 & 20,61 & 20,43 & 0,97 & 76,64 \\
\hline \multirow{2}{*}{$\begin{array}{l}6 \mathrm{~s}-8 \mathrm{~s} \\
1.200 \mathrm{rpm}\end{array}$} & TR4 & 16,64 & 20,82 & 20,22 & 0,36 & 28,17 \\
\hline & SS4 & 19,04 & 20,01 & 19,53 & 0,99 & 58,25 \\
\hline \multirow{2}{*}{$\begin{array}{l}8 \mathrm{~s}-10 \mathrm{~s} \\
1.000 \mathrm{rpm}\end{array}$} & TR5 & 18,65 & 19,42 & 19,04 & 1,20 & 66,13 \\
\hline & SS5 & 18,35 & 19,46 & 18,93 & 1,06 & 71,75 \\
\hline
\end{tabular}

TR=Transient; SS=Steady-State; $\mathrm{P}=$ Active Power; $\mathrm{Q}=$ Reactive Power; S=Apparent Power; $\mathrm{RS}=$ Rotor Speed; Tem=Electromagnetic Torque

The chattering reduction in constant rotor speed test with variable torque loads shown in table 3. In no-load condition, the rotor speed response has $0,15 \%$ of chattering reduction in transient condition and $0,45 \%$ in a steady-state condition. This value is much smaller than the chattering reduction in electromagnetic torque. This chattering reduction increase significantly in rotor speed response with the transient condition but a decrease in a steady-state condition. The electromagnetic torque response has decreased along with the addition of torque load. This chattering impact on reduced power consumption. In power analysis, the active power consumption in no-load condition decreases $39,46 \%$ while the reactive and apparent powers are $30,16 \%$ and $34,89 \%$. In variable torque loads response, the power reduction decreases $33,14 \%$ in active power, $23,02 \%$ and in apparent power $17,03 \%$ under $0,5 \mathrm{Nm}$ of torque load. This value significantly reduces at $1 \mathrm{Nm}$ and $1,5 \mathrm{Nm}$ torque loads. In $1 \mathrm{Nm}$ torque load, the power reduction is $19,83 \%$ while the reactive and apparent powers are $14,39 \%$ and $17,03 \%$, respectively. This power reduction continues to decline on 1,5 Nm of torque load (active power reduction is $8,08 \%$, reactive power reduction $2,36 \%$ and apparent power reduction $5,19 \%$ ). Impairment in power reduction because of the saturation function cannot withstand robustness and stability when the response out of the sliding region. The variable rotor speed reference test with constant reference torque load consists of two results, the power reduction and chattering reduction. The chattering reduction analysis in rotor speed and electromagnetic torque response while the power reduction analysis in active, reactive and apparent power. In starting conditions (TR1) the chattering reduction of rotor speed is $0,49 \%$. This reduction compensate the $28,85 \%$ of active power reduction, $14,45 \%$ of reactive power reduction and $24,17 \%$ of apparent power reduction. In electromagnetic torque response, the chattering reduction is $30,07 \%$. At SS1, the chattering reduction of rotor speed and electromagnetic torque are $0,55 \%$ and $70,56 \%$. At this step, the saturation function save $23,59 \%$ of active power, reduce the reactive and apparent power by $21,92 \%$ and $23,00 \%$. The biggest chattering reduction in rotor speed and electromagnetic torque is in transient response of breaking process from $1.350 \mathrm{rpm}$ to $900 \mathrm{rpm}$. This step saves $20,83 \%$ of active power.

\section{Conclusion}

The paper aims at the effect of boundary layers in robust FOSMC placed on the rotor speed controller while the current regulator and flux controller use FOSMC. The boundary layer uses 
the saturation function to compare with sign function in FOSMC. The upper limit of the saturation function is the sign function and the lower limit is $S_{1}(\Omega r) / \beta_{l}$. The results focus on the robustness test and influence of chattering reduction on the power consumption of FOSMC in constant and variable rotor speed reference with various torque loads. The robustness test of constant rotor speed reference with various torque load shows that the error steady-state in rotor speed less than $2 \%$ both in FOSMC using sign and saturation function. At a variable rotor speed reference test with a torque load of $1 \mathrm{Nm}$, the robustness of FOSMC shown in figure 9. Based on Tables 3 and 4, the boundary layer gives the chattering reduction and power saving in constant rotor speed reference with various torque and variable rotor speed reference with constant torque. On the other hand, the boundary layer cannot withstand robustness and stability when the response exits the sliding region. The future works of this research are chattering free analysis in second-order and high order robust SMC applied in the IFOC system for IM.

\section{Acknowledgements}

The authors thanks to Electric Machine and Control Laboratory - Politeknik Elektronika Negeri Surabaya (PENS).

\section{References}

[1] M. D. Martin, F. Luise, S. Pieri, A. Tessarolo and C. Poloni, "Numerical multi-objective optimization of a squirrel cage induction motor for industrial application," in Intl Conference on Electrical Machines \& Power Electronics (ACEMP), Intl Conference on Optimization of Electrical \& Electronic Equipment (OPTIM) \& Intl Symposium on Advanced Electromechanical Motion Systems (ELECTROMOTION), Side, 2015.

[2] V. K. Pavuluri, X. Wangy, J. Longz, G. Zhuox and W. Lian, "Field Oriented Control of Induction Motors Using Symmetrical Optimum Method with Applications in Hybrid Electric Vehicles," in IEEE Vehicle Power and Propulsion Conference (VPPC), Montreal, 2015.

[3] M. Zeraoulia, M. E. H. Benbouzid and D. Diallo, "Electric Motor Drive Selection Issues for HEV Propulsion Systems: A Comparative Study," IEEE Transactions on Vehicular Technology, vol. 55, no. 6, pp. 1756 - 1764, 2006.

[4] Z. Yang, F. Shang, I. P. Brown and M. Krishnamurthy, "Comparative Study of Interior Permanent Magnet, Induction and Switched reluctance Motor Drives for EV and HEV Applications," IEEE Transactions on Transportation Electrification, pp. 245 - 254, 2015.

[5] G. Sieklucki, "An Investigation into the Induction Motor of Tesla Model S Vehicle," in International Symposium on Electrical Machines (SME), Andrychów, 2018.

[6] B. K. Bose, Modern Power Electronics and AC Drives, Prentice Hall, 2001.

[7] Y. B. Zbede, S. M. Gadoue and D. J. Atkinson, "Model Predictive MRAS Estimator for Sensorless Induction Motor Drives," IEEE Transactions on Industrial Electronics, vol. 63, no. 6, pp. 3511-3521, 2016.

[8] H. Abu-Rub, A. Iqbal and J. Guzinski, High Performance Control of AC Drives with MATLAB/Simulink Models, West Sussex: John Wiley \& Sons Ltd, 2012.

[9] L. Taneja, S. Kumar and R. Kumar, "Current Regulated Induction Motor Drive with IFOC," in IEEE 6th India International Conference on Power Electronics (IICPE), Kurukshetra, 2014.

[10] K. Zeb, W. U. D. M. A. Khan, A. Khan, U. Younas, T. D. C. Busarello and H. J. Kim, "Dynamic Simulations of Adaptive Design Approaches to Control the Speed of an Induction Machine Considering Parameter Uncertainties and External Perturbations," Energies, vol. 11, no. 9, p. 2339, 2018. 
[11] Y. Shu-ying, Y. Shu, X. Zhen, M. Ming-yao and Z. Xing, "A New Vector Control Strategy of Induction Motor based on Iron Loss Model," in Chinese Automation Congress, Jinan, 2017.

[12] A. Testa, S. D. Caro, S. Foti, T. Scimone and G. Scelba, "On-line Rotor Time Constant Estimation in IFOC Induction Motor Drives," in 2018 International Symposium on Power Electronics, Electrical Drives, Automation and Motion (SPEEDAM), Amalfi, 2018.

[13] T. Bedi, D. Heema and D. Singh, "A Comparative Analysis of Digital and Passive Filters for IFOC based Induction Motor Drive (EV) fed through ZSI," in 3rd International Conference on Communication Systems (ICCS-2017), Pilani, 2017.

[14] K. Bouhoune, K. Yazid, M. Boucherit and A. Cheriti, "Hybrid Control of the Three Phase Induction Machine using Artificial Neural Networks and Fuzzy Logic," Applied Soft Computing, vol. 55, pp. 289 - 301, 2017.

[15] H. Aziri, F. A. Patakor, M. Sulaiman and Z. Salleh, "Comparison Performances of Indirect Field Oriented Control for Three-Phase Induction Motor Drives," International Journal of Power Electronics and Drive System (IJPEDS), vol. 8, no. 4, pp. 1682 - 1692, 2017.

[16] I. Ferdiansyah, M. R. Rusli, B. Praharsena, H. Toar, Ridwan and E. Purwanto, "Speed Control of Three Phase Induction Motor Using Indirect Field Oriented Control Based on Real-Time Control System," in International Conference on Information Technology and Electrical Engineering (ICITEE), Bali, 2018.

[17] I. Ferdiansyah, E. Purwanto and N. A. Windarko, "Fuzzy Gain Scheduling of PID (FGSPID) for Speed Control Three Phase Induction Motor Based on Indirect Field Oriented Control (IFOC)," EMITTER International Journal of Engineering Technology, vol. 4, no. 2, pp. 237-258, 2016.

[18] R. Fauzi, D. C. Happyanto and I. A. Sulistijono, "Fast Response Three Phase Induction Motor Using Indirect Field Oriented Control (IFOC) Based On Fuzzy-Backstepping," EMITTER International Journal of Engineering Technology, vol. 3, no. 1, pp. 92-114, 2015.

[19] M. A. Hannan, J. A. Ali, A. Mohamed, U. A. U. Amirulddin, N. M. L. Tan and M. N. Uddin, "Quantum-Behaved Lightning Search Algorithm to Improve Indirect FieldOriented Fuzzy-PI Control for IM Drive," IEEE Transactions on Industry Applications, vol. 54, no. 4, pp. 3793-3805, July-Aug. 2018.

[20] B. Sumantri, N. Uchiyama and S. Sano, "Robust Tracking Control of a Quad-Rotor Helicopter Utilizing Sliding Mode Control with a Nonlinear Sliding Surface," Journal of Systems Design and Dynamics, vol. 7, no. 2, pp. 226-241, 2013.

[21] N. M. Noaman, "Speed Control for IFOC Induction Machine with Robust Sliding Mode Controller," Asian Journal of Scientific Research, vol. 1, no. 4, pp. 324-337, 2008.

[22] A. W. Aditya, D. C. Happyanto and B. Sumantri, "Application of Sliding Mode Control in Indirect Field Oriented Control for Model Based Controller," EMITTER International Journal of Engineering Technology, vol. 5, no. 2, pp. 255-269, 2017.

[23] B. Sumantri, N. Uchiyama and S. Sano, "Least Square Based Sliding Mode Control for a Quad-Rotor Helicopter*," in IEEE/SICE International Symposium on System Integration, Kobe, 2013.

[24] A. W. Aditya, R. M. Utomo, Hilmansyah, M. R. Rusli and B. Praharsena, "Power performance of boundary technique on FOSMC based induction motor drives," in International Conference on Applied Science and Technology (iCAST on Engineering Science), Bali, 2019. 
[25] E. Quintero-Manríquez, E. N. Sanchez and R. A. Félix, "Real-Time Direct Field-Oriented and Second Order Sliding Mode Controllers of Induction Motor for Electric Vehicles Applications," in System of Systems Engineering Conference (SoSE), Texas, 2015.

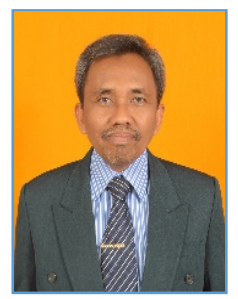

Dedid Cahya Happyanto was born in Pasuruan, East Java, Indonesia, on December 27, 1962. He is a lecturer in the Department of Electronic Engineering, Politeknik Elektronika Negeri Surabaya (PENS). He received a bachelor degree from Institute of Technology Sepuluh Nopember Surabaya, Indonesia (1986), Master Engineering (MT) from Electrical Engineering Institute of Technology Sepuluh Nopember Surabaya, Surabaya, Indonesia (2002), and a Ph.D. degree in Department of Electrical Engineering from the Institute of Technology Sepuluh Nopember Surabaya Indonesia (2012). His research interest includes Intelligent Control, Electric machines and Electrical Power Drive.

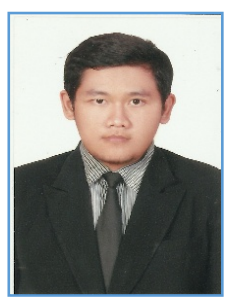

Angga Wahyu Aditya is a lecturer of Politeknik Negeri Balikpapan (POLTEKBA), Indonesia. He received bachelor degree in Electrical Engineering from Politeknik Elektronika Negeri Surabaya (PENS), Surabaya, Indonesia, in 2016, a master's degree in Electrical Engineering from Politeknik Elektronika Negeri Surabaya (PENS), Surabaya, Indonesia, in 2018. His research interest is in power electronics, electric machines, electrical drive, and robust control systems.

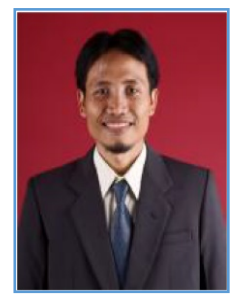

Bambang Sumantri is a lecturer of Politeknik Elektronika Negeri Surabaya (PENS), Indonesia. He received bachelor degree in Electrical Engineering from Institut Teknologi Sepuluh Nopember (ITS), Indonesia, in 2002, M.Sc (Master of Science) in Control Engineering from Universiti Teknologi Petronas, Malaysia, in 2009, and Doctor of Engineering in Mechanical Engineering, Toyohashi University of Technology, Japan, in 2015. His research interest is in robust control system, robotics, and embedded control system. 